\title{
Improving the Mechanical Properties of 304 Stainless Steel Using Waterjet Peening
}

\author{
Yun ZOU, Zhenkuan SANG, Qilong WANG, Tingchao LI, Dalei LI, Yang LI* \\ School of Mechanical Engineering, Zhengzhou University, Zhengzhou 450001, P R China \\ crossref http://dx.doi.org/10.5755/j01.ms.26.2.21117
}

Received 02 July 2018; accepted 10 November 2018

\begin{abstract}
In this study, waterjet peening (WJP) treatments under different water pressures were utilized to improve the mechanical properties of 304 stainless steel. The surface morphologies, microstructures, phases, and mechanical properties under different pressures in the WJP process were systematically investigated. The results show that WJP treatments successfully introduced a hardening layer and residual compressive stress. The optimal hardening layer, hardness, residual compressive stress, tensile strength, and ductility were all recorded at the pressure of $200 \mathrm{MPa}$. The improved hardness, tensile strength, and ductility of 304 stainless steel treated with WJP treatments at the pressure of $200 \mathrm{MPa}$ can be attributed to the hardening layer with much apparent grain refinement effect, phase transformation, smaller surface roughness, and a specific residual compressive stress, as compared with the WJP treatments under other water pressures.

Keywords: 304 stainless steel, waterjet peening, microstructure, mechanical properties.
\end{abstract}

\section{INTRODUCTION}

In general, the material failure occurs on the material surface. Therefore, the improvement of material properties depends on its surface properties [1]. In recent years, the use of surface deformation strengthening methods to generate beneficial microstructure and residual stress changes to induce property enhancement has made many achievements, such as the widespread use of shot peening (SP) [2], laser shot peening (LSP) [3, 4], surface mechanical attrition treatment (SMAT) [5], surface mechanical grinding treatment (SMGT) [6], and ultrasonic nanocrystal surface modification (UNSM) [7-9]. The surface deformation strengthening technology is mainly through a certain mechanical means to make the material surface occur a certain degree of plastic deformation, lead the surface layer of the material to form a certain depth of the deformation layer, and then improve the material properties [3].

Waterjet peening (WJP) is a metal strengthening technology based on surface deformation strengthening mechanism. It is a mechanical surface strengthening process where high-frequent impact of water drops on the surface of metal material, which causes local plastic deformation below the recrystallization temperature. As a result, the material surface forms a certain depth of deformation layer, which leads to the enhanced surface hardness and fatigue life of materials by introducing compressive residual stresses [10].

Arola et al. [11-13] employed abrasive waterjet peening to treat titanium alloy Ti6Al4V, pure titanium cpTi, and AISI304 stainless steel, respectively. They obtained the variation law of the surface residual compressive stress, roughness, and stress concentration coefficient with WJP process parameters such as pressure and abrasive size also proved the endurance strength of the Ti6Al4V was increased from $680 \mathrm{MPa}$ to $875 \mathrm{MPa}$ (25\% increase) under the optimum treatment conditions.

Azhari et al. [10, 14] studied the effects of WJP process parameters, e.g. pressure, speed, and multi-nozzle on the surface state of 304 stainless steel, and they obtained the depth of the hardened layer under different WJP conditions by determining the hardness in the depth direction. They also studied multiple steps in WJP treatment and then proved that the combined action of surface hardening and smoothing using numerous steps in WJP treatment is useful in increasing the hardness and reducing the roughness of the surface.

Kunaporn et al. $[15,16]$ used pure high-pressure waterjet to strengthen the aluminum alloy and studied the effects of three types of nozzle structures on the surface state of the material. They proved that waterjet could improve the fatigue strength and delay the crack by the fatigue test. They also showed that materials with higher tensile strength tended to have greater fatigue benefit from peening process.

Compared with other surface deformation strengthening technology methods such as SP, LSP, SMAT, SMGT, and UNSM, WJP could be used to process samples with complexed shapes and achieve good surface finish due to the easily controllable processing parameters, which has great potential applications in various industrial fields $[17,18]$.

At present, the researches on WJP mainly focused on surface fatigue properties and fatigue crack extension. However, researches on the surface microstructures and tensile properties treated by WJP are rarely studied. In this paper, the effects of WJP treatments under different water pressures on the surface morphologies, microstructures, phases, and mechanical properties of 304 stainless steel were systematically investigated.

\footnotetext{
* Corresponding author. Tel.: +86-0371-67781752.

E-mail address:yangli@zzu.edu.cn (Y. LI)
} 


\section{EXPERIMENTAL DETAILS}

\subsection{Materials}

For the current study, 304 stainless steel with the measured chemical composition of $0.068 \mathrm{C}, 0.58 \mathrm{Si}$, $0.71 \mathrm{Mn}, 0.024 \mathrm{P}, 0.004 \mathrm{~S}, 18.20 \mathrm{Cr}, 8.45 \mathrm{Ni}$, and balance $\mathrm{Fe}$ (in wt.\%), was used. To obtain the austenite coarse grain structure, a solution treatment was performed at $1363 \mathrm{~K}$ for $60 \mathrm{~min}$, followed by water quenching. The solution-treated specimens were abraded with $\mathrm{SiC}$ papers, followed by ultrasonic cleaning in acetone for $15 \mathrm{~min}$ to remove soil and/or grease, to obtain an original average surface roughness $R \mathrm{a}$ of $0.25 \mu \mathrm{m}$.

\subsection{WJP surface modification experiments}

The WJP surface treatment experiments were carried out on the DWJ1525-FC waterjet machine, which is capable of generating pressure from $80 \mathrm{MPa}$ to $350 \mathrm{MPa}$. The nozzle geometry used in this experiment is a round one with a diameter of $1.0 \mathrm{~mm}$, and the nozzle moving speed is less than $8 \mathrm{~m} / \mathrm{min}$. The incidence angle was set at $90^{\circ}$, i.e., the nozzle was perpendicular to the specimen surface. The medium was pure water without the use of abrasives to obtain surfaces free of embedded abrasive particles. The chosen WJP strengthening parameters were based on our preliminary four factors four levels orthogonal experiment (L16) with parameters of water pressure (150, 200, 250, $300 \mathrm{MPa})$, target distance $(5,10,15,20 \mathrm{~mm})$, speed $(400$, $600,800,1000 \mathrm{~mm} / \mathrm{min})$, and feed $(0.125,0.25,0.5$, $1.0 \mathrm{~mm})$. The results showed that the sequence of the four factors for the surface residual stress, surface hardness, and surface roughness was: water pressure $\approx$ feed $>$ speed $>$ target distance. Thus, we chose the water pressure as the only variable to evaluate the effect of water pressure on the water jet strengthening behaviors. The water pressure is $100,150,200,250,300 \mathrm{MPa}$. The rest of the parameters were constant, that is, the speed $400 \mathrm{~mm} / \mathrm{min}$, target distance $15 \mathrm{~mm}$, feed $0.25 \mathrm{~mm}$. Besides, we also prepared the corresponding untreated specimen for comparison.

\subsection{Characterizations}

The microstructures were analyzed using the optical microscopy (OM) and scanning electron microscopy (SEM, Zeiss Auriga Compact). The XRD analysis was obtained via $\mathrm{X}$-ray diffraction equipment (Ultima IV) using $\mathrm{Cu}-\mathrm{Ka}$ radiation. The generator settings were $40 \mathrm{kV}$ and $30 \mathrm{~mA}$, the diffraction data were collected over a $2 \theta$ range of $40-80^{\circ}$, with a step width of $0.02^{\circ}$ and a scan speed of $8^{\circ}$ per minute. The 3D surface topographies and surface roughness ( $\mathrm{Ra}$ ) of the materials were measured by NPFLE 3D surface topography system (Bruker Nano Inc). A measurement area of about $2529 \times 1897 \mu^{2}$ was covered. Light and dark colors indicated peak and valley regions, respectively. The surface roughness $(\mathrm{Ra})$ is an average of at least five roughness values. To reveal the subsurface microstructure, the samples were metallographically grinding and polishing, followed by etching in aqua regia.

The magnitude of the induced residual compressive stress of the material surface before and after WJP treatment was conducted with Proto LDR standard high-speed X-ray residual stress analyzer (PROTO) using Mn-K $\alpha$ radiation and the XRD system was calibrated by a stress-free sample. The roll method was selected in the test, and the fixed angle $\psi$ angle is used in the scanning mode, the $\psi$ angle is $0^{\circ}$, $11.8^{\circ},-11.8^{\circ}, 17.48^{\circ},-17.48^{\circ}, 25^{\circ},-25^{\circ}$, an average of at least five residual compressive stresses data was recorded.

The distribution of hardness along the WJP surface to the base of the specimens was measured using HV-1000 hardness tester with a force of $100 \mathrm{~g}$ using a diamond pyramid indenter for $15 \mathrm{~s}$. An average of at least five hardness data was recorded at every depth.

Tension tests were performed on an MTS material tester (MTS 370.02) with a strain rate of $1 \times 10^{-3} \mathrm{~s}-1$ at room temperature. An extensometer was applied during the tests. The gauge length, width, and thickness of the tensile specimens are 12.5, 5, and $2 \mathrm{~mm}$, respectively. Both of the two opposite faces of the gauge area were processed by WJP treatments, where it may experience the highest stress concentration.

\section{RESULTS AND DISCUSSION}

\subsection{Surface morphology, microstructures, and phase analysis}

\subsubsection{Surface morphology}

Fig. 1 shows the 3D surface topographies of specimens treated under different pressures, a much more severe erosion can be seen after treatment with higher pressure.

It is well-known that the water supply pressure is directly proportional to the impingement velocity of the water droplet [10], that is, the kinetic energy of the water molecules increases with a higher water pressure. It can be deduced that the more severe impact on the surface of the material will cause the more severe plastic deformation, resulting in more severe stress concentration, which will make the surface of material produce many micro-cracks, finally, some micro-cracks will remove the wrapped material. Therefore, the higher pressure will increase the ability to remove the material.

Fig. 2 shows the effect of pressure on the surface roughness of the specimens, where the surface roughness $R \mathrm{a}$ is the arithmetic mean roughness value. It can be seen that the surface roughness almost keeps the same value from 0 (original) to $200 \mathrm{MPa}$, while the surface roughness suddenly increases when the pressure exceeds $200 \mathrm{MPa}$, and then increases continuously until it reaches its maximum value of $19.6 \mu \mathrm{m}$ at $300 \mathrm{MPa}$. That is, the higher pressure will iimprove the ability to remove the material and then increase the surface roughness of the material.

\subsubsection{Microstructures and phase analysis}

Fig. 3 shows the cross-sectional microstructures of the specimens treated under 0 (original), 150, 200, and $250 \mathrm{MPa}$. It can be seen from the figure that the average grain size of the original material is about $65 \mu \mathrm{m}$ (Fig. $3 \mathrm{a}$ ), and the cross-sectional microstructure of WJP specimen has no change at the pressure of $150 \mathrm{MPa}$ (Fig. $3 \mathrm{~b}$ ), as compared with the original specimen. It can infer that the cross-sectional microstructure of the specimen under $100 \mathrm{MPa}$ pressure has no change. 

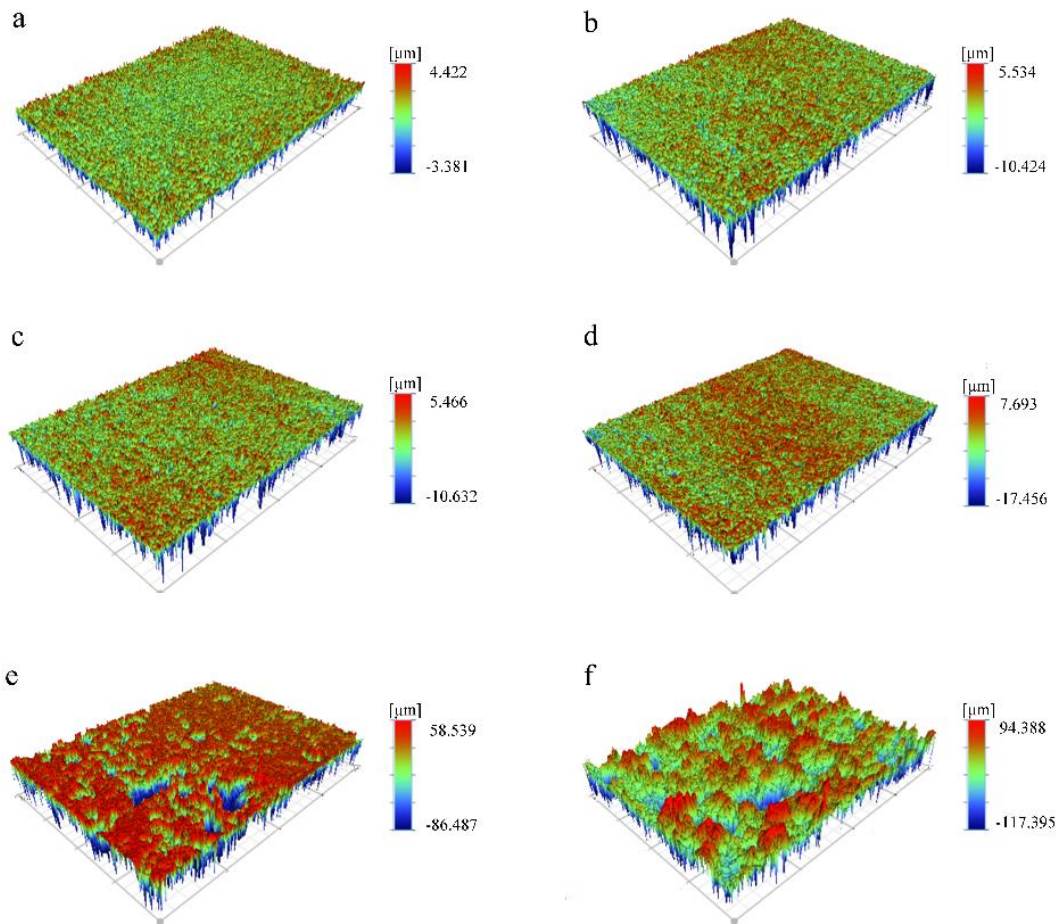

Fig. 1. The 3D surface topographies of specimens treated under different pressures: a-0 MPa; $b-100 \mathrm{MPa} ; \mathrm{c}-150 \mathrm{MPa} ; \mathrm{d}-200 \mathrm{MPa}$; e-250 MPa; $-300 \mathrm{MPa}$

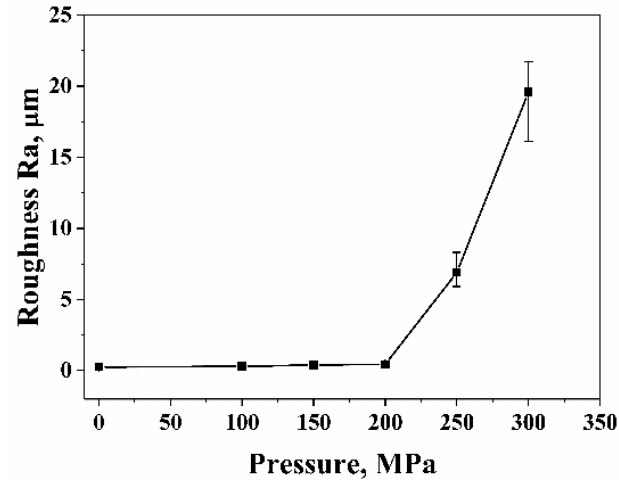

Fig. 2. The effect of pressure on the surface roughness Ra of the specimens

However, there is about $80 \mu \mathrm{m}$ deformation layer in the cross-section of the WJP specimen at the pressure of $200 \mathrm{MPa}$ (Fig. $3 \mathrm{c}$ ), and the near-surface grain was significantly refined after the WJP treatments. Severe erosion occurs at the upper edge of the picture of WJP specimen at the pressure of $250 \mathrm{MPa}$ (Fig. 3d), which is in agreement with the 3D surface topographies and surface roughness measurement results. It can infer that the erosion at $300 \mathrm{MPa}$ pressure is more dangerous. Fig. 4 shows the surface microstructures of the specimens treated under 150 , 200 and $250 \mathrm{MPa}$ taken by SEM, and the average grain size was statistical analysis by the intercept method using Image $\mathrm{J}$ software. The average grain size of the surface layer of the WJP area under $150 \mathrm{MPa}$ is about $65 \mu \mathrm{m}$ (Fig. 4 a). That is to say, there is little change in the surface microstructures of WJP specimen at the pressure of $150 \mathrm{MPa}$, as compared with the original specimen (Fig. 3 a). The surface layer average grain size of the specimen under $200 \mathrm{MPa}$ is about
$6 \mu \mathrm{m}$ (Fig. 4 b), decreasing by $90.7 \%$, as compared to that of the original specimen. While the grain boundaries of the specimen under $250 \mathrm{MPa}$ become blurred and there is severe erosion (Fig. $4 \mathrm{c}$ ). That is, when the pressure is too high, an increase in jet pressure promotes growth in the jet energy available for hydrodynamic erosion.

It can be deduced that the optimized conditions of WJP can refine grain size by observing the microstructures of the specimens. Many researchers reported that the twining was a prevalent deformation mechanism of 304 stainless steel by severe plastic deformation for the grain refinement [19], and some researchers also reported that martensitic transformation occurred in the heavily twinned microstructures [20]. Thus, the XRD qualitative analysis of phases of 304 stainless steel treated under pressure of 150 , 200, and $250 \mathrm{MPa}$ was conducted, as shown in Fig. 5. Because 304 stainless steel is austenitic stainless steel, the original specimen only consisted of an austenite phase after the solution treatment. The two peaks (M110 and M200), corresponding to martensite appeared after the WJP treatments, indicating that martensite phase transformation was induced by the WJP treatments.

\subsection{Mechanical properties}

\subsubsection{Surface residual stress}

The compressive residual stress is a significant characterization of surface properties, which is beneficial to improve the resistance to fatigue crack initiation. The surface residual stresses of the specimens treated under different water pressures were measured by XRD. The test principle is based on the produced residual stress in crystalline materials will lead to interplanar spacing change, and thus, it can be accessed indirectly by measuring dspacing $\sin ^{2} \psi$. 


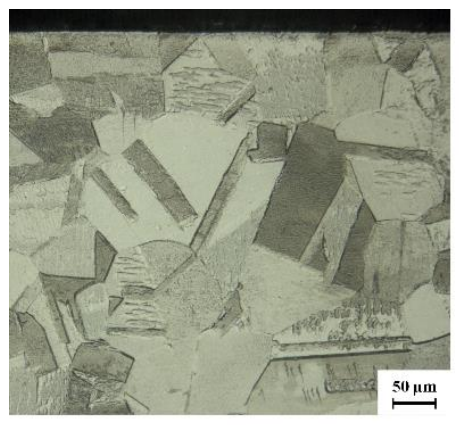

a

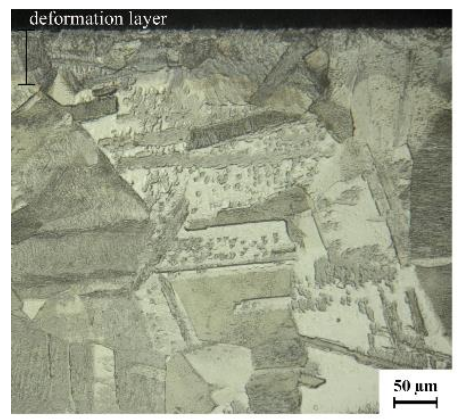

$\mathrm{c}$

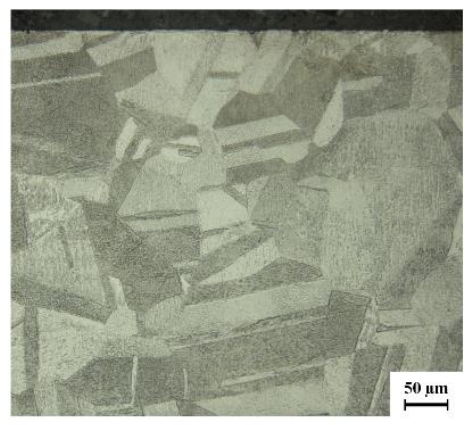

b

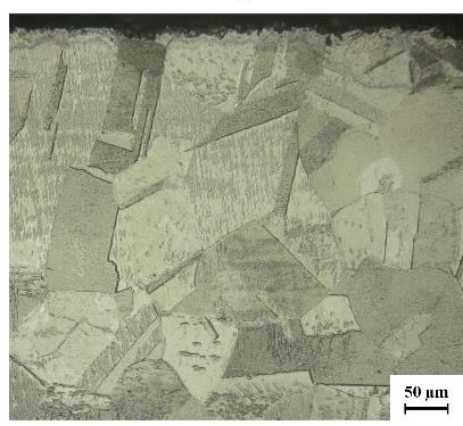

d

Fig. 3. The cross-sectional microstructures of specimens treated under: a-0 (original); b-150 MPa; c-200 MPa; d-250 MPa

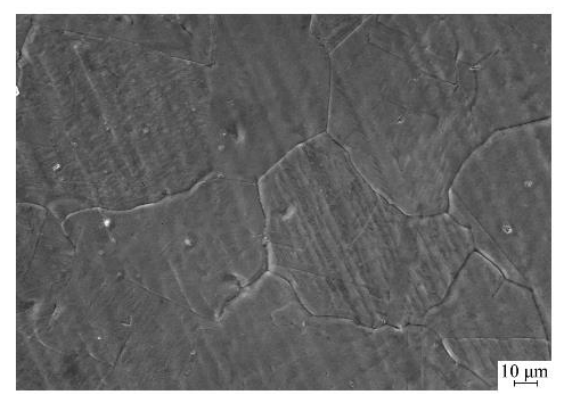

a

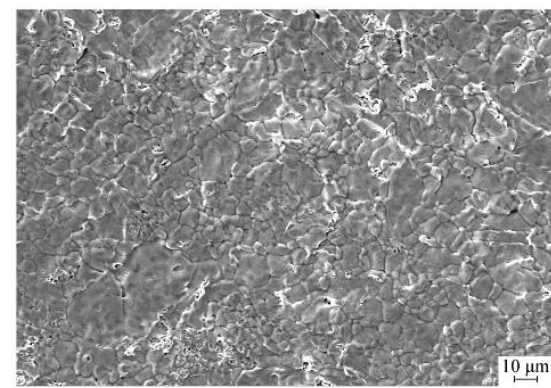

$\mathrm{b}$

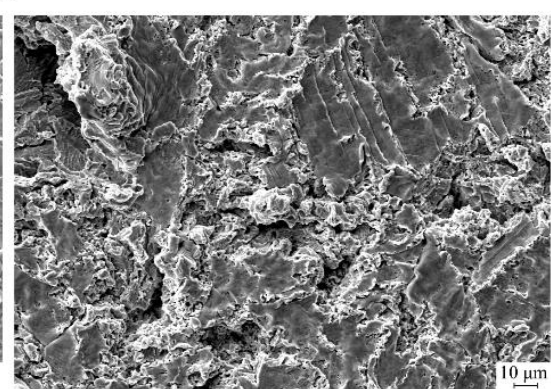

Fig. 4. The surface microstructures of the specimens treated under: a-150 MPa; b-200 MPa; $c-250 \mathrm{MPa}$

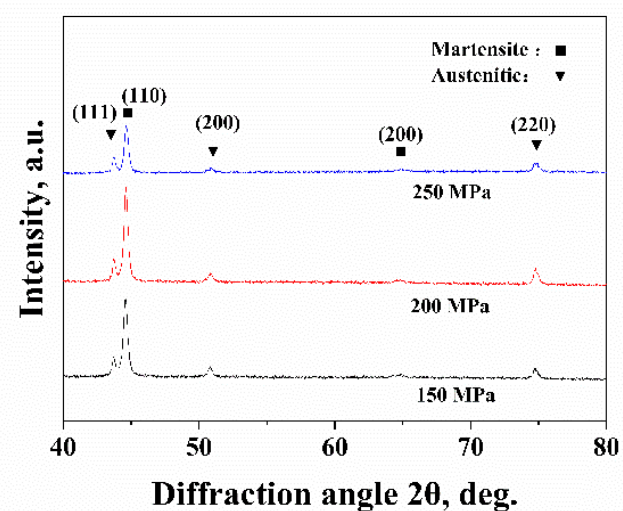

Fig. 5. X-ray diffraction patterns of specimens treated under $150 \mathrm{MPa}, 200 \mathrm{MPa}$, and $250 \mathrm{MPa}$
This is the most popular technique used for measuring residual stress by XRD method, where diffraction peak is determined at the high range of $2 \theta$ angles, then the XRD system is adjusted in this angle and d-spacing of crystal planes is measured in different positions [21]. In fact, the workpiece is tilted at the different $\psi$ angles, and d-spacing is measured in each rotation. The residual stresses were calculated after mathematical simplifications as [21]:

$$
\sigma=\frac{E}{(1+v) \sin ^{2} \psi}\left[\frac{d_{\psi}-d_{0}}{d_{0}}\right]
$$

where $\sigma$ is residual stress, $E$ is Young's modulus, $v$ is Poisson's ratio, $d_{0}$ is d-spacing of stress-free crystal planes, 
and $d_{\psi}$ is $d$ spacing of stressed crystal planes in $\psi$ direction. The measured surface residual stresses result of the specimens treated under different water pressures are shown in Fig. 6.

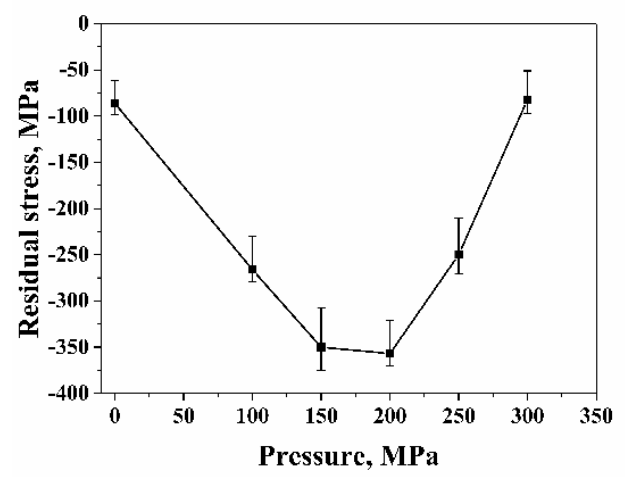

Fig. 6. The residual surface stress of the specimens treated under different water pressure

It can be seen that the increasing pressure induces higher residual compressive stress under relatively low pressure ( 0 to $200 \mathrm{MPa}$ ), the maximum average residual compressive stress is about $-357 \mathrm{MPa}$ at the water pressure of $200 \mathrm{MPa}$. When the water pressure exceeds $200 \mathrm{MPa}$, the residual compressive stress exhibits a downward trend along with the increase of water pressure and decreases to the almost same residual stress value of the original material when the water pressure reaches $300 \mathrm{MPa}$. The compressive residual stresses were induced due to local plastic deformation caused by high-frequent impact of water drops on the surface of the material. When the water pressure is relatively low, the plastic deformation becomes more significant with the increase of the water pressure, leading to higher residual compressive stress. When the pressure is relatively high, an increase in jet pressure promotes growth in the jet energy available for hydrodynamic erosion. Consequently, material removal allowed near-surface stress relief of the surface layers and resulted in a reduction in the magnitude of compressive stress. This is consistent with the results reported by Arola et al. [13] that the residual compressive stress exhibits a downward trend along with the increase of water pressure using abrasive waterjet peening.

\subsubsection{Hardness}

The hardness depth profiles of 304 stainless steel specimens processed under different water pressures (Fig. 7 c) and corresponding indentation picture of hardness test (Fig. 7 a, b) are shown in Fig. 7. Hardness measurement was acquired on the jet impinged surface and the crosssections of the specimens at different depths starting from $50 \mu \mathrm{m}$ beneath the jet impinged surface until a far distance of about $500 \mu \mathrm{m}$. In general, the hardness depth profiles for all conditions show a similar trend with the hardness decreasing gradually from the surface. It can be seen that the hardening layer may extend up to a depth of about $350 \mu \mathrm{m}$, the maximum depth of hardening layer is close to $400 \mu \mathrm{m}$ at the water pressure of $200 \mathrm{MPa}$. It is worth noting that there is one exception of a specimen treated with the highest pressure of $300 \mathrm{MPa}$, where the hardness profile is nearly horizontal due to the excessive pressure can peel off the produced hardened layer. The maximum hardness was recorded to be $231,258,281,251$, and $210 \mathrm{HV} 0.1$ at pressure of 100, 150, 200, 250, and $300 \mathrm{MPa}$, respectively, increased by $18.5,32.3,44.1,28.7$, and $7.7 \%$, in comparison with the base material (about 195 HV0.1). Based on the hardness depth profiles, the hardening layer may extend slightly thicker at the initial stage, especially in the case of the pressure of $200 \mathrm{MPa}$, but when the pressure continued to increase, a reverse effect on the subsurface hardness and hardening layer depth was found. It can be concluded that increasing the pressure would produce higher hardness as well as deeper hardening layer at the initial stage. The increase in the hardness and thickness of the hardening layer is due to higher waterjet impact force, which causes local plastic deformation. As a result, high compressive residual stresses are induced in the surfacenear layer, which leads to enhanced surface hardness. When the pressure is too high, an increase in jet pressure promotes growth in the jet energy available for hydrodynamic erosion, peeling the hardened layer off, and thus actually reduces the hardness. This is consistent with the result reported by Azhari et al. [10] that increasing the pressure would produce higher hardness and deeper hardening layer. Besides, this study indicates that the excessive water pressure will lead to the hardness and thickness of hardening layer to decrease.

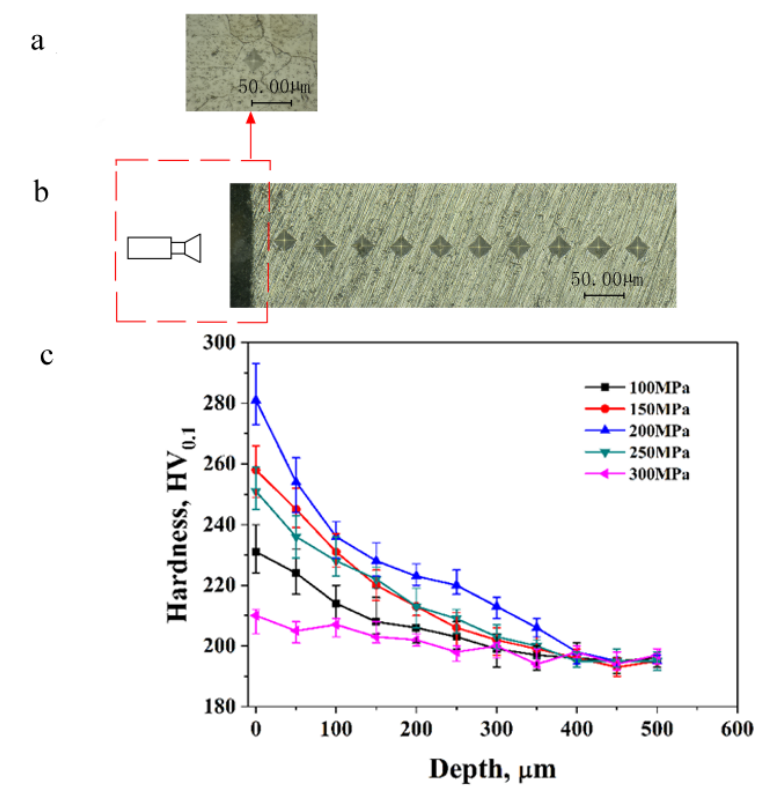

Fig. 7. $a-$ the corresponding indentation picture of hardness test of surface; $b$-corresponding indentation picture of hardness test of the cross-sections; c - hardness depth profiles of 304 stainless steel specimens under different water pressures

\subsubsection{Tensile properties}

The engineering stress-strain curves of the specimens treated under different WJP conditions tested at ambient temperature are demonstrated in Fig. 8. The tensile yield strength (TYS) of specimens after WJP at the pressure of 0 (original), 100, 150, 200, 250, and $300 \mathrm{MPa}$ are 212, 237, $252,255,241$, and $205 \mathrm{MPa}$, respectively. The corresponding ultimate tensile strength (UTS) of these specimens are 784, 835, 842, 848, 808, and $715 \mathrm{MPa}$. And the corresponding elongations to fracture (Ef) of these specimens are 66, 69, 71, 72, 71, and $64 \%$. That is, the WJP 
makes the TYS, UTS, and Ef of the consistent material trend, all of them show the trend of first increase than reduce with water pressure. The maximum TYS, UTS, and Ef are $255 \mathrm{MPa}, 848 \mathrm{MPa}$, and $72 \%$, respectively, at the pressure of $200 \mathrm{MPa}$, increased by $20.2 \%, 8.2 \%$, and $9.1 \%$, in comparison with the untreated specimen. At the same time, when the pressure is $300 \mathrm{MPa}$, the TYS, UTS, and Ef of the specimen drop to the minimum of $205 \mathrm{MPa}, 715 \mathrm{MPa}$, and $64 \%$, respectively, which is lower than that of the untreated specimen.

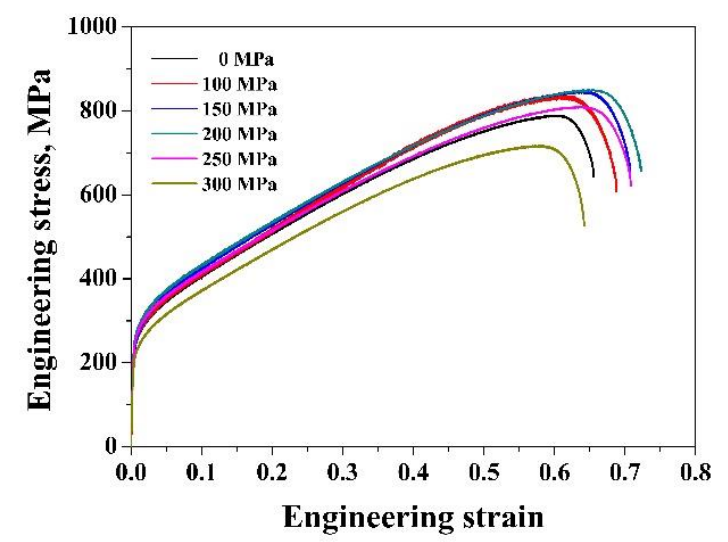

Fig. 8. The engineering stress-strain curves of the specimens under different WJP conditions at ambient temperature

Combing with the compressive residual stresses and hardness results above, with the high-frequent impact of water drops on the surface of the material, causing local plastic deformation. As a result, compressive residual stress is induced in the surface-near layer, which leads to enhanced surface hardness. The improved hardness can improve the mechanical properties of materials by improving the resistance to plastic deformation. At the same time, the residual compressive stresses not only offset or reduce applied tensile stresses or slow crack growth but also transfer the maximum tensile stress from the surface to the subsurface, which results in the crack initiation source is transferred to some defective areas of the subsurface $[12,22]$. As the magnitude of the compressive stress and the hardness increase, so usually does the resistance to crack.

A large number of studies have shown that the strength and plasticity of the material are closely related to the grain size of the material, the smaller the grain size, the higher the strength of the material $[23,24]$. On the one hand, grain refinement is equivalent to enlarging the grain boundary area, and the grain boundary is an obstacle to dislocation movement. Therefore, the smaller the grain size and the more grain boundary, the higher the hindrance to the dislocation movement and the higher the strength of the material. Meantime, grain refinement increases the number of grains per unit volume. The same deformation can be dispersed to more grains, resulting in a more uniform deformation without causing excessive local stress concentration, causing premature initiation of the crack with the extension. On the other hand, grain refinement reduces the size of defects in the material, thereby improving the overall performance of the material.

However, when the pressure is too high, the strength and plasticity of the material tend to decrease with an increase in jet pressure, it can be anticipated that bombardment of the surface with the WJP often leads to many cracks or flaws due to the rise of roughness, which may outweigh the beneficial enhancement effect. Thus, the strengthening of material should be taken by optimized conditions of WJP.

\section{CONCLUSIONS}

WJP treatments under different water pressures were utilized to improve the mechanical properties of 304 stainless steel. According to the combined analyses of surface morphologies, microstructures, phases, and mechanical properties results, some conclusions can be drawn as follows:

1. The grain refinement and martensitic transformation were observed after WJP treatments. Hardening layer and residual compressive stress were successfully introduced by WJP treatments. The smallest grain size decreasing by $90.7 \%$, and the highest increase of hardness up to $44.1 \%$, as compared to that of the base material. The deepest hardening layer up to a depth of about $400 \mu \mathrm{m}$ and the maximum average residual compressive stress is $-357 \mathrm{MPa}$. All the optimal data were recorded at the pressure of $200 \mathrm{MPa}$.

2. The room temperature tensile test shows that the reasonable WJP process can improve the tensile properties of 304 stainless steel. The optimal yield strength, tensile strength, and elongation are $255 \mathrm{MPa}$, $848 \mathrm{MPa}$, and $72 \%$, respectively, at the pressure of 200 $\mathrm{MPa}$, increased by $20.2 \%, 8.2 \%$, and $9.1 \%$, in comparison with the untreated specimen.

3. The improved hardness, tensile strength, and ductility of 304 stainless steel treated with WJP treatments at the pressure of $200 \mathrm{MPa}$ can be attributed to the hardening layer with much noticeable grain refinement effect, phase transformation, smaller surface roughness, and a specific residual compressive stress.

\section{Acknowledgments}

This work was supported by the National Science Foundation of China under Grant 51705470 and 51801185; Key Research Project of the Higher Education Institutions of Henan Province, Henan Provincial Department of Education, China, under Grant 18A460032; and Special Research and Promotion Project of Henan Province, China, under Grant 182102210009.

\section{REFERENCES}

1. Liu, G., Wang, S.C., Lou, X.F., Lu, J., Lu, K. Low Carbon Steel with Nanostructured Surface Layer Induced by Highenergy Shot Peening Scripta Materialia 44 (8) 2001: pp. $1791-1795$. https://doi.org/10.1016/S1359-6462(01)00738-2

2. Tumbajoy-Spinel, D., Maeder, X., Guillonneau, G., SaoJoao, S., Descartes, S., Bergheau, J., Langlade, C., Michler, J., Kermouche, G. Microstructural and Micromechanical Investigations of Surface Strengthening Mechanisms Induced by Repeated Impacts on Pure Iron Materials \& Design 147 2018: pp. 56-64. https://doi.org/10.1016/j.matdes.2018.03.014 
3. Wu, J.F., Zou, S.K., Zhang, Y.K., Gong, S.L., Sun, G.F., Ni, Z.H., Cao, Z.W., Che, Z.G., Feng, A.X. Microstructures and Mechanical Properties of $\beta$ Forging Ti17 Alloy under Combined Laser Shock Processing and Shot Peening Surface \& Coatings Technology 328 2017: pp. $283-291$.

https://doi.org/10.1016/j.surfcoat.2017.08.069

4. Zhou, L.C., He, W.F., Luo, S.H., Long, C.B., Wang, C., Nie, X.F., He, G.Y., Shen, X.J., Li, Y.H. Laser Shock Peening Induced Surface Nanocrystallization and Martensite Transformation in Austenitic Stainless Steel Journal of Alloys and Compounds 655 2016: pp. 66-70.

https://doi.org/10.1016/j.jallcom.2015.06.268

5. Bajda, S., Ratuszek, W., Krzyzanowski, M., Retraint, D. Inhomogeneity of Plastic Deformation in Austenitic Stainless Steel after Surface Mechanical Attrition Treatment Surface \& Coatings Technology 329 2017: pp. 202-211. https://doi.org/10.1016/j.surfcoat.2017.09.049

6. Huang, H.W., Wang, Z.B., Yong, X.P., Lu, K. Enhancing Torsion Fatigue Behavior of a Martensitic Stainless Steel by Generating Gradient Nanograined Layer via Surface Mechanical Grinding Treatment Materials Science and Technology 29 (10) 2013: pp. 1200-1205. https://doi.org/10.1179/1743284712Y.0000000192

7. Ma, C., Qin, H.F., Ren, Z.C., O'Keeffe, S.C., Stevick, J., Doll, G.L., Dong, Y.L., Winiarski, B., Ye, C. Increasing Fracture Strength in Bulk Metallic Glasses Using Ultrasonic Nanocrystal Surface Modification Journal of Alloys and Compounds 718 2017: pp. 246-253.

https://doi.org/10.1016/j.jallcom.2017.05.056

8. Hou, X.N., Qin, H.F., Gao, H.Y., Mankoci, S., Zhang, R.X., $\quad$ Zhou, X.F., $\quad$ Ren, Z.C., $\quad$ Doll, G.L., Martini, A., Sahai, N. A Systematic Study of Mechanical Properties, Corrosion Behavior and Biocompatibility of AZ31B Mg Alloy after Ultrasonic Nanocrystal Surface Modification Materials Science and Engineering C 78 2017: pp. $1061-1071$.

https://doi.org/10.1016/j.msec.2017.04.128

9. Amanov, A., Urmanov, B., Amanov, T., Pyun, Y.S. Strengthening of Ti-6Al-4V Alloy by High Temperature Ultrasonic Nanocrystal Surface Modification Technique Materials Letters 196 2017: pp. 198-201. https://doi.org/10.1016/j.matlet.2017.03.059

10. Azhari, A., Schindler, C., Kerscher, E., Grad, P. Improving Surface Hardness of Austenitic Stainless Steel Using Waterjet Peening Process International Journal of Advanced Manufacturing Technology $63(9-12)$ 2012: pp. $1035-1046$. https://doi.org/10.1007/s00170-012-3962-1

11. Arola, D., McCain, M.L. Abrasive Waterjet Peening: A New Method of Surface Preparation for Metal Orthopedic Implants Journal of Biomedical Materials Research 53 (5) 2000: pp. 536-546.

https://doi.org/10.1002/1097-4636(200009)53:5<536::aidjbm13>3.0.co;2-v

12. Arola, D., Alade, A.E., Weber, W. Improving Fatigue Strength of Metals Using Abrasive Waterjet Peening Machining Science \& Technology $10(2)$ 2006: pp. $197-218$. https://doi.org/10.1080/10910340600710105

13. Arola, D., McCain, M.L., Kunaporn, S., Ramulu, M. Waterjet and Abrasive Waterjet Surface Treatment of
Titanium: a Comparison of Surface Texture and Residual Stress Wear $249(10-11)$ 2001: pp. 943-950. https://doi.org/10.1016/S0043-1648(01)00826-2

14. Azhari, A., Schindler, C., Hilbert, K., Godard, C., Kerscher, E. Influence of Waterjet Peening and Smoothing on the Material Surface and Properties of Stainless Steel 304 Surface and Coatings Technology 258 2014: pp. $1176-1182$. https://doi.org/10.1016/j.surfcoat.2014.07.013

15. Kunaporn, S., Chillman, A., Ramulu, M., Hashish, M. Effect of Waterjet Formation on Surface Preparation and Profiling of Aluminum Alloy Wear 265 (1) 2008: pp. 176-185.

https://doi.org/10.1016/j.wear.2007.09.008

16. Ramulu, M., Kunaporn, S., Jenkins, M., Hashish, M., Hopkins, J. Fatigue Performance of High-Pressure Waterjet-Peened Aluminum Alloy Journal of Pressure Vessel Technology 124 (1) 2002: pp. 118-123. https://doi.org/10.1115/1.1398553

17. Azhari, A., Schindler, C., Li, B. Effect of Waterjet Peening on Aluminum Alloy 5005 International Journal of Advanced Manufacturing Technology $67(1-4)$ 2013: pp. $785-795$. https://doi.org/10.1007/s00170-012-4522-4

18. Rajesh, N., Babu, N.R. Multidroplet Impact Model for Prediction of Residual Stresses in Water Jet Peening of Materials Materials and Manufacturing Processes 21 (4) 2006: pp. 399-409. https://doi.org/10.1080/10426910500411736

19. Zhang, H.W., Hei, Z.K., Liu, G., Lu, J., Lu, K. Formation of Nanostructured Surface Layer on AISI 304 Stainless Steel by Means of Surface Mechanical Attrition Treatment Acta Materialia 51 (7) 2003: pp. 1871-1881. https://doi.org/10.1016/s1359-6454(02)00594-3

20. Byun, T.S., Lee, E.H., Hunn, J.D. Plastic Deformation in 316LN Stainless Steel - Characterization of Deformation Microstructures Journal of Nuclear Materials 321 (1) 2003: pp. 29-39. https://doi.org/10.1016/S0022-3115(03)00195-8

21. Anderoglu, O. Residual Stress Measurement Using X-Ray Diffraction. Thesis, Texas A\&M University, 2004

22. Lieblich, M., Barriuso, S., Ibáñez, J., Ruiz-de-Lara, L., Díaz, M., Ocaña, J.L., Alberdi, A., GonzálezCarrasco, J.L. On the Fatigue Behavior of Medical Ti6Al4V Roughened by Grit Blasting and Abrasiveless Waterjet Peening Journal of the Mechanical Behavior of Biomedical Materials 63 2016: pp. 390-398. https://doi.org/10.1016/j.jmbbm.2016.07.011

23. Roland, T., Retraint, D., Lu, K., Lu J. Enhanced Mechanical Behavior of a Nanocrystallised Stainless Steel and Its Thermal Stability Materials Science and Engineering: A 445-446 (6) 2007: pp. 281-288. https://doi.org/10.1016/j.msea.2006.09.041

24. Hakamada, M., Nakamoto, Y., Matsumoto, H., Iwasaki, H., Chen, Y.Q., Kusuda, H., Mabuchi, M. Relationship between Hardness and Grain Size in Electrodeposited Copper Films Materials Science and Engineering: A 457 (1) 2007: pp. 120-126. https://doi.org/10.1016/j.msea.2006.12.101 